\title{
Psychological Climate Among Women Hockey Players And It Is Relationship With The Anxiety Of Motivation And Performance
}

\author{
By \\ Dr. Hoda Abd-ElHamid Abd-EIWahab Mohamed \\ Assistant Professor of Educational and Social Sciences Department - Faculty of \\ Physical Education (girls)
}

\section{Abstract}

This research aims to identify the psychological Climate for hockey players team, the excellent class and its relationship concerned about motivation and the level of skills performance, the basic research sample was selected randomly, from the Hockey Players team at Al Sharkia Club and they were recorded in Hockey Federation for the year (2015 2016), Who participated in the league and cup double, they are (17) players, the Descriptive method was used because it is suitable for the aim of the research, The most important results that the dominant psychological climate for the players of hockey team (the excellent class), It is a psychological positive climate, there is a positive close relationship with statistically significant, between the psychological climate and The level of motivation anxiety, also there is a positive close relationship with statistically significant, between the psychological climate, The level of motivation anxiety, and the level of skills performance for the hockey players team (the excellent class).

Key words: motivation anxiety - the level of skills performance.

\section{Introduction}

Despite scientific advances in the preparation of athletes physically, tactically with skills. Psychological factor remains the decisive variable in athletic performance, so the sports psychology is a necessary science, for the advancement of training process, and sports competitions. Study the team's performance in sports activities depends on joint operations analysis, In the formation of a skilled performance and looking for the development of skills, and trying to diagnose the different factors that determine the success aspects in the level of skills performance, (Yahya Kadhim alNaqib, 1990).

Osama Kamel Rateb, refers to That the psychological aspect plays a major role in raising the level of performance. And it is regarded the psychological side as one of the variables that must took care of it, side by side with the physical and skill and tactical requirements, Whereas the sporting excellence depends on how the players take advantage of the psychological abilities, with a manner that does not reduce the benefit from physical and skill abilities. (Osama Kamel Rateb 2001).

The psychological climate for sports team is one of the contemporary and important topics, usually when we describe the air or the weather or the climate we might describe it as a sunny or Daffy or beautiful or we may describe it as windy or rainy or cold or bad or otherwise of different qualities. In the field of sports psychology, it can be used for such qualities, to describe the kind of the interaction for individuals within a single sports team, and The nature of the contact with each other, how their sense of belonging to the team, and the quality of 
its relationship with sports leadership of the team.

"Allawy" citing "James, Hartman Jones" Indicates that, the psychological climate for the sports team is a component and psychological Composition, and How the player can realize the relationships between Sports team members, which can each player in the team evaluate it clearly. While The perception of the player for his team psychological climate has the importance in influencing the direction of feeling each player satisfaction. And therefore to stay as a member of the team that produces sports team cohesion greatly (Mohammad Hassan Allawy, 1998).

A good psychological climate for sports team shows, through a sense of belonging to the players for the team, and loyalty to it, and to stick to its membership, and dedication to achieve its goals, and take responsibility, and regularity of the team members, and their integration into the training and motivation toward matches. (Ahmad Fawzi Amin, Tariq Badr al-Din, 2001).

"Allawy" citing "David Francis, Donald Young" Indicates that, the Sports team is not a group of players dressed in a robe united, but it is far from it, as it is an active group of individuals who have committed to the completion of certain objectives, and work together proactively to provide high results of value, and that those responsible for team sports should use the ways and means to try creating harmony between the team members, and provide a good psychological climate since the beginning of the process of forming the structure of the team. So to be grouped players together on the basis of an important factor, which is the interaction between the players that is so-called psychological climate, so as to ensure accessing more effectiveness of the sports team, then psychological climate describes the quality of individual interaction inside a single sporting team, the nature of the contact among them, how their sense of belonging to the team, and the quality of their relationship with sports leadership of the team. (Mohammad Hassan Allawy, 1998).

"Osama Kamel Rateb" refers to the importance of knowing the coach of effective procedures, which contribute to creating the psychological conditions, that helps to develop team spirit, to achieve cohesion among the players, and taking into account that the change of psychological climate for the team requires sufficient time. (Osama Kamel Rateb 1997).

So the creation of psychological climate for the players before participating in sports competitions constitutes as target and procedure simultaneously, where, and all the procedure taken during training operations aims to the psychological preparation of the players of the team to participate in the competitions. (Ahmad Fawzi Amin, Tariq Badr al-Din, 2001).

"Newton Newton" indicates that, psychological climate is closely linked to the educational climate system, and to the meanings and self-explanations, that the players Concluded from their experience in their clubs, training, and matches, so these interpretations affect the direction of the motivation and the level of skill performance, therefore determines the goal that they must seek to achieve in the psychological climate. (Newton Newton 1997).

"Ahmed Amin Fawzy and Tariq Badr al-Din" That is what indicates that it must the sports environment evoke the motivations of athlete towards the team, it is through the psychological climate and positive interaction among the team which make every player aware of the importance of the team's success, which in turn leads to the pursuit of behavior that leads to the success of the team, and to avoid anything that may lead to failure. (Ahmed Amin Fawzy, Tariq Badr al-Din 2001). 
Factors that affect the psychological climate for sports team are all united, including the fear of making mistakes, or anxiety, and anxiety is an emotionally charged case unpleasant associated excitation resulting from fear, or expectation of danger and increasing concern about the amount to be, leading to confusion athletic performance, and disability and vice versa, a decrease level of anxiety leads to indifference in the face of situations, but if the amount of anxiety is suitable for the position which faces the player that was perfect to issue the desired behavior to cope with situations, the anxiety here is a positive element of motivation, anxiety motivation is the kind of anxiety which is characterized by the appropriate intensity, and then the appropriate excitation, which helps to cope with situations experienced by the player, for the issuance of appropriate behavior and achieve the best results. (Amin Ahmad Fawzi, 2003).

Sports anxiety is a psychological variable that important for the athlete, which should maintain its stability, and trying to invest it, as a positive motivator to achieve the best sports results. (Mohammad Hassan Allawy, 1992).

Faruk Osman indicates that anxiety is the motivation of the important motivations, which helps to success, achievement, excellence, Anxiety motivation is a promotional characteristic to complete the tasks, and indicates that there is a relationship between the level of anxiety and the level of performance, so reaches the level of performance to the peak, when the player reaches the required level of anxiety. ( Faruk Al sayed Osman, 2001).

Whenever the team players have the ability to cohesion, and confront crises faced by their team, whenever this has led to the ability to respond to threats, to achieve the goal of the team, and reach the required results, (Abdel Monem Shehata, 2002).

\section{"Osama Kamel \\ Rateb" \\ (1990),"Mahmoud \\ Annan" (1995),"Mostafa Bahy " and Others"} (2006) indicate that the concern one of the important emotions, which passes by the player before and during athletic competition, and has the function of a refresher as well as negative effects, If better controlled, and directed so the player reaches the required level of anxiety before and during the match serve as the positive driving force for performance, but the player must explain the concern as a healthy phenomenon, it is called the facilitator concern or motivation anxiety, which leads to a level of performance and better results, and former world champion in skating, "Steve Bodbo Rsky" said that the severity of my concern and tension of my nerves destroy my ability to performance, (Osama Kamel Rateb, 1990) (Mahmoud Annan, 1995) (Mostafa Bahy and Samir Gad, 2006).

Hockey Sport is one of the fastest sports highly skilled, which provides fun for practitioners at any ages, knowing the rules of the game, and the special skills is not enough to perform well, it must the player be able to apply his knowledge and skills, and assesses the extent of his progress and his relationship with the rest of his colleagues, which raises motivation to make more effort to raise the level of skill performance, so he can help his team during the matches, (Ellen Wadih Farah, 2008).

Activity of women's hockey has begun in Egypt in year (1994), to form the first national team for them, and took part in the third African Nations Championship in year (1998), the team ranked fourth after South Africa, Kenya, and Zimbabwe. (Alia Azmi Shawky, 2008).

We can find that hockey is one of the neglected and forgotten sports in Egypt, despite the successes of this sport, through a team is a true legend in the Egyptian sports sky, which is the Sharkia Hockey team and its achievements, that the world 
talking about, and that was undercounted in Egypt suitable appreciation or highlight on it, or interesting in conducting scientific research studies, while it has entered the team as the first Arab and African registered in The Guinness Book of Records in the field of fishing the tournaments, After the team won 47 hockey tournaments, including 22 African championships out of 25 established by the African Union for the game until 2015 and 20 championships in the Premier League, and 7 championships Egypt Cup, and there are two clubs in Sharkia Governorate have Misses hockey team take part in domestic league and they are (the Sharkia club Sadat Center for Youth), the club of Sharkia Hockey for Misses team won in the Premier League, and the Cup, so they will be qualifying for the African Championship this year, and to be held in Namibia.

The researcher believes that the sports commander should be a good helper, and assistant to the players, through creating the psychological climate for the players, which helps to remove the anxiety and tension from the hearts of the players in case of feeling of negative emotions, And inappropriate responses from the sports commander, such as criticism, or sarcasm, or demonized, or non-recognition of the submitted effort, so It can be resulted as a bad climate among the players, the sports team members, The pressures that can be put by sports commander, (trainers - the administrative system), and parents, through the insistence on making achievements, and the need to win, and the achievement of the objectives may outweigh the athletes capabilities, (physical - skill - psychological), is one of the things that may call for anxiety, stress, and high arousal clearly, and send in the hearts of the players, fear of making mistakes, Thereby creating an unhealthy climate among the players, characterized by the excess emotions, fear of failure, lack of self-confidence, on the contrary, that the sports trainer confession of individual effort for players, In the framework of teamwork, and justice, and equality among players of a single sports team, and allow the players to take some decisions independently, All this factors that enhance the player's confidence in himself , and helps to strength the personal connections among the players, that working on improve the responsibility of the player toward the team, whenever athlete assured, felt safe, and satisfaction , whenever more likely to achieve sporting excellence, and it will not be achieved only through climate change, which prepares the coach for the players, and further helps to increase their motivation, that leads to the fact that anxiety is positive that means it is a motivation.

Anxiety motivation is one of the important emotions that affect the performance of the players, especially in sports competitions, despite the differences in factors, sources of anxiety, but many researchers link it to the implications of the environment, or psychological climate that surrounding players, which called on the researcher to conduct this study, The Sharkia hockey team for Misses, which features in the tournaments harvest, to try to identify the psychological climate of the team, and its relationship with motivation anxiety, the level of skill performance.

\section{The research aim}

- Identifying the psychological climate among players of Sharkia hockey team, Premier League.

- The study of the relationship between psychological climate and motivation anxiety for the players of Sharkia hockey team, Premier League.

- The study of the relationship between psychological climate and the level of skill performance for the players of Sharkia hockey team, Premier League. 
- The study of the relationship between motivation anxiety and the level of skill performance for the players of Sharkia hockey team, Premier League.

\section{Research hypotheses}

- There is a statistically significant correlation between psychological climate and the level of motivation anxiety for the players of Sharkia hockey team (Premier League).

- There is a statistically significant correlation between psychological climate and the level of skill performance for the players of Sharkia hockey team (Premier League).

- There is a statistically significant correlation between the level of motivation anxiety and the level of skill performance for the players of Sharkia hockey team (Premier League).

\section{Procedures}

\section{Method}

The researcher used the descriptive method for being suitable for the research aims.

\section{Community and the research sample:}

Research community consists of players Team Hockey for Misses at Sharkia Club and they were recorded in Hockey Federation for the year 2015 2016 they are (29) player was chosen purposively, they are the players who have taken part in the league and the cup, their team was raised, and will participate in the African championship in Namibia in the month of $11 / 2016$, the researcher made an exploratory sample randomly, contains of (12) players, so as to find a scientific coefficients of search tools, and thus the Basic sample of the research became (17) players.

The following table shows that, the torsion coefficients for research community variables (age - Training age psychological climate - motivation anxiety - the level of skill performance) have ranged from $( \pm 3)$ which indicates the equinoctial distribution for research community in these measurements.

Table (1) shows that all torsion coefficients values, are confined between $( \pm 3)$, which indicates the moderation of repetition distribution of the variables (age Training age - psychological climate - motivation anxiety - The level of skill performance).

Table (1) Moderation of repetition distribution for research community in the variables (age - Training age - psychosocial climate - motivation anxiety - the level of skill performance) $\mathrm{N}=(\mathbf{2 9})$

\begin{tabular}{|c|c|c|c|c|c|}
\hline Parameter & $\begin{array}{c}\text { Measuring } \\
\text { Unit }\end{array}$ & Average & SD & Mediator & $\begin{array}{c}\text { Torsion } \\
\text { modulus }\end{array}$ \\
\hline Age & Year & 18.17 & 19.00 & 1.92 & -0.455 \\
\hline Training age & Year & 9.51 & 9.00 & 1.47 & 0.640 \\
\hline Psychosocial climate degree & Degree & 92.51 & 92.00 & 3.55 & 1.867 \\
\hline $\begin{array}{c}\text { Motivation anxiety degree } \\
\text { The level of skill } \\
\text { performance }\end{array}$ & Degree & 84.89 & 87.00 & 7.68 & -0.804 \\
\hline & Degree & 85.06 & 88.00 & 6.91 & -0.873 \\
\hline
\end{tabular}




\section{Measures}

\section{First: the psychological climate measure: Attachment (1)}

It has been designed by "Mohammad Hassan Allawy," in 1995, it aims to identify the nature of the psychological climate or the atmosphere, that characterizes the sports team, and it includes the measure (20) characteristics, and their opposites, then the player has to answer on the measure according to the degree of his belief in identical of these qualities on the psychological climate in which he lives with his sports team, which he belongs on a measure of (7) degrees, the degrees of each player have been collected, and his grades on the measure as a whole, in the light of the correction key, can also be obtained on the degrees of psychological climate for the team as a whole, in each characteristic and their opposites, collecting degrees of the team to be divided by the number of players in the team. (Mohammad Hassan Allawy, 1995).

Second: The measurement of motivation anxiety for the athletes (the behavior of the competition): Attachment (2).

Also it designed by "Mohammad Hassan Allawy," and aims to identify the extent of the contribution of anxiety to the promote of the level of athlete performance, especially during athletic competition includes (20) phrases, and the player responds to phrases test, the fivedegrees scale is ranging from (always) to (never) and taking into account that the test address is (the behavior of the competition) and includes a test (10) phrases in the direction of the sense of motivation anxiety in promoting the level of performance, the phrases numbers are $(17,15,14,13,12,9,8,6,1,20)$ and always is
(5 ) degrees, and (never) is one degree, It also includes test (10) phrases are opposite the motivation anxiety, that means in the direction of obstruction anxiety to the level of the player's performance, the phrases numbers are $(19,18,16,11,10,7,5,4,3,2)$ (always) equal one degree, and (never) equal 5 degrees, Indicates that the contribution of anxiety to the promoting the level of performance, especially in sports competitions . (Mohammad Hassan Allawy and Kamal Al Din Darwish and others 2003).

\section{Expeditionary study}

The researcher conducted an exploratory study, in order to identify the suitability of psychological measurements phrase under application of the research community, as well as to find the scientific coefficients of research tools on exploratory study sample representing the research community, and outside the core sample for research, it was (12) players, so in the period from Monday 07/11/2016 to Wednesday, 13/07/2016.

\section{Validity measurement}

To check the veracity of the psychological climate measurement, and test motivation anxiety for the athletes, the researcher has conducted the sincerity of differentiation using comparison the peripheral between the degrees of the outstanding players, and the nonoutstanding players, the measurements under discussion, degrees of players were arranged in descending order, find the significance of differences between the two parts, the following table shows the arithmetic average, standard deviation, and the value of " $\mathrm{T}$ " between the highest degrees and the lowest degrees in the psychological climate measurement, and the test of motivation anxiety for athletes (Validity). 
Table (2) the arithmetic average, standard deviation, and the value of (T) between the highest degrees and the lowest degrees in the psychological climate measurement, and the test of motivation anxiety for athletes.

\begin{tabular}{|c|c|c|c|c|}
\hline \multicolumn{5}{c}{$\mathbf{N} 1=\mathbf{N} 2=6$} \\
Parameter & $\begin{array}{c}\text { Measuring } \\
\text { Unit }\end{array}$ & $\begin{array}{c}\text { Spearman } \\
\text { prawn }\end{array}$ & Guttmann & $\begin{array}{c}\text { The } \\
\text { coefficient } \\
\text { of alpha } \\
\text { Cronbach }\end{array}$ \\
\hline $\begin{array}{c}\text { The psychological } \\
\text { climate measurement }\end{array}$ & Degree & 0.645 & 0.695 & 0.754 \\
\hline $\begin{array}{c}\text { Motivation anxiety } \\
\text { measurement }\end{array}$ & Degree & 0.599 & 0.630 & 0.684 \\
\hline
\end{tabular}

Table (2) shows that there are statistically significant differences at the (0.05) level between the highest degrees and the lowest degrees in the measurements under discussion, in a favor of the owners of the highest degrees, indicating her ability to distinguish between the players which shows her veracity.

\section{Reliability}

To find a the stability coefficient of psychological climate measurement, and test of motivation anxiety for the athletes, the researcher using the half retail method Spearman prawn, Guttmann, the method of Alpha, the method of testing and re-testing as the table (3) and (4) show, The table below shows the half retail stability, The coefficient of "alpha Cronbach" for psychological climate measurement, and test of motivation anxiety for the athletes.

Table (3)

The half retail stability, The coefficient of "alpha Cronbach" for psychological climate measurement, and test of motivation anxiety for the athletes.

$$
\mathbf{N}=\mathbf{1 2}
$$

\begin{tabular}{|c|c|c|c|c|c|c|c|}
\hline Parameter & $\begin{array}{l}\text { Measuri } \\
\text { ng Unit }\end{array}$ & \multicolumn{2}{|c|}{ Highest degrees } & \multicolumn{2}{|c|}{$\begin{array}{l}\text { Lowest } \\
\text { degrees }\end{array}$} & $\begin{array}{c}\text { The } \\
\text { difference } \\
\text { between }\end{array}$ & $\begin{array}{c}\mathbf{T} \\
\text { Value }\end{array}$ \\
\hline $\begin{array}{c}\text { The psychological climate } \\
\text { measurement }\end{array}$ & Degree & 89.50 & $\mathbf{0 . 8 3}$ & 92.50 & 1.37 & 3.00 & 4.557 \\
\hline Motivation anxiety measurement & Degree & 74.66 & 4.67 & 88.00 & 5.65 & 13.14 & 4.450 \\
\hline
\end{tabular}

The value of tabulated $(R)$ at the level $0.05=0.576$.

Table (3) shows that the correlation coefficients ranged between $(0.630,0.695)$ the equation of Spearman - Brown, has ranged between $(0.599,0.645)$ the equation of "Guttmann", has ranged between $(0.684,0.754)$ with the equation of alpha Cronbach, which shows that psychological measurements under discussion have a high-stability coefficient.

The table below shows the correlation coefficient Spearman's method, between the first and second applications, psychological climate measurements, and motivation anxiety (stability). 
Table (4)

Correlation coefficient between the first and second applications for the psychological climate and motivation anxiety measurements.

$\mathbf{N}=\mathbf{1 2}$

\begin{tabular}{|c|c|c|c|c|c|c|}
\hline & Tests & \multicolumn{2}{|c|}{ First application } & \multicolumn{2}{|c|}{$\begin{array}{l}\text { Second } \\
\text { application }\end{array}$} & R Value \\
\hline 1 & $\begin{array}{c}\text { The psychological climate } \\
\text { measurement }\end{array}$ & 90.83 & 1.94 & 91.00 & 1.90 & 0.710 \\
\hline 2 & Motivation anxiety measurement & 81.33 & 8.54 & 81.66 & 8.56 & 0.988 \\
\hline
\end{tabular}

The value of tabulated $(R)$ at the level $0.05=0.576$

Table (4) shows that the correlation coefficients between the first and second applications, ranged between (0998, 0710), which shows that psychological measurements under discussion have a high-stability coefficient.

Third: the level of skill performance of the players:

The level of skill performance the players' degrees have been obtained, hockey team for Misses the coach of the team, the highest degree is (100) degrees, that's after they win the league and cup.

\section{Participant}

After the researcher has being confirmed for the research tools have high scientific coefficients, the researcher has applied them to the basic sample for the research, (17) players, in the period on Sunday, $17 / 07 / 2016$ to the Tuesday, 19/07/2016. Then the researcher unloaded data, and preparation the degrees for statistical processing.

\section{results}

Table (5) shows that the higher arithmetic averages for all items of psychological climate measurement, with the exception of (lack of incentives), and (instability). 
Table (5)

Statistical characterization for the sample basic research, in the items psychological climate measurements.

\begin{tabular}{|c|c|c|c|c|c|}
\hline \multicolumn{6}{|c|}{$\mathbf{N}=\mathbf{1 7}$} \\
\hline & Items & Average & Mediator & $\begin{array}{l}\text { Standard } \\
\text { deviation }\end{array}$ & $\begin{array}{l}\text { Torsion } \\
\text { modulus }\end{array}$ \\
\hline 1 & Cohesion / non-cohesion & 5.249 & 5.00 & 1.312 & 0.242 \\
\hline 2 & Lack of cooperation / cooperation & 5.764 & 6.00 & 1.091 & -1.107 \\
\hline 3 & Satisfaction / dissatisfaction & 6.412 & 7.00 & 0.870 & 1.629 \\
\hline 4 & Ineffectiveness / effectiveness & 4.529 & 5.00 & 0.717 & -0.115 \\
\hline 5 & Boring/ Exciting & 5.471 & 6.00 & 1.463 & -0.545 \\
\hline 6 & Success feeling / failure feeling & 5.412 & 6.00 & 1.661 & 0.568 \\
\hline 7 & Approval / interception & 5.294 & 5.00 & 1.047 & 0.068 \\
\hline 8 & Instability / stability & 1.824 & 2.00 & 0.727 & 0.290 \\
\hline 9 & Convergence / divergence & 5.177 & 5.00 & 1.425 & 0.203 \\
\hline 10 & Non-affiliation / affiliation & 6.412 & 6.00 & 1.118 & -1.105 \\
\hline 11 & $\begin{array}{c}\text { Attractive relations / non-attractive } \\
\text { relations }\end{array}$ & 6.059 & 7.00 & 1.298 & 1.289 \\
\hline 12 & $\begin{array}{c}\text { Successful leadership / unsuccessful } \\
\text { leadership }\end{array}$ & 4.882 & 5.00 & 0.928 & -1.321 \\
\hline 13 & Non-reciprocal / mutual connection & 5.294 & 6.00 & 1.105 & -0.665 \\
\hline 14 & $\begin{array}{c}\text { Common traditions / different } \\
\text { traditions }\end{array}$ & 5.235 & 5.00 & 1.201 & 0.255 \\
\hline 15 & $\begin{array}{l}\text { The performance of individual / } \\
\text { collective performance }\end{array}$ & 5.705 & 6.00 & 1.160 & -0.162 \\
\hline 16 & Disharmony / harmony & 5.471 & 6.00 & 1.505 & -0.435 \\
\hline 17 & Clarity of roles / ambiguity of roles & 3.824 & 4.00 & 1.380 & -0.614 \\
\hline 18 & Positive / negative & 5.353 & 6.00 & 1.578 & 0.558 \\
\hline 19 & Clear objectives / unclear objectives & 5.235 & 5.00 & 1.480 & 0.066 \\
\hline 20 & Lack of incentives / presence incentives & 2.647 & 3.00 & 1.272 & 0.143 \\
\hline
\end{tabular}

Table (5) shows that all torsion coefficients values, confined between $( \pm 3)$ which indicates moderation of repetition distribution, for the sample of basic research on the items of psychological climate measurements.
Table (6) shows that the correlation coefficient between the psychological climate, anxiety motivation for hockey players, and its statistically significant positive value at level of significance (0.05). 
Table (6)

The correlation coefficient between the psychological climate measurements, and motivation anxiety

$$
\mathbf{N}=\mathbf{1 7}
$$

\begin{tabular}{|c|c|c|c|c|}
\hline \multicolumn{2}{|c|}{$\begin{array}{c}\text { The psychological climate } \\
\text { measurement }\end{array}$} & \multicolumn{2}{|c|}{ The level of skill performance } & R Value \\
\hline 93.58 & 4.07 & 88.88 & 3.38 & 0.819 \\
\hline
\end{tabular}

The value of tabulated $(R)$ at the level $0.05=0.482$

Table (6) shows that the correlation coefficient between the psychological climate, motivation anxiety for hockey players, it's statistically significant positive value at level of significance (0.05).

Table (7) shows that the correlation coefficient between the psychological climate, the level of skill performance for hockey players, its statistically significant positive value at level of significance $(0.05)$.

The correlation coefficient between the psychological climate measurement, and the level of skill performance.

$$
\mathbf{N}=17
$$

The value of tabulated $(R)$ at the level $0.05=0.482$

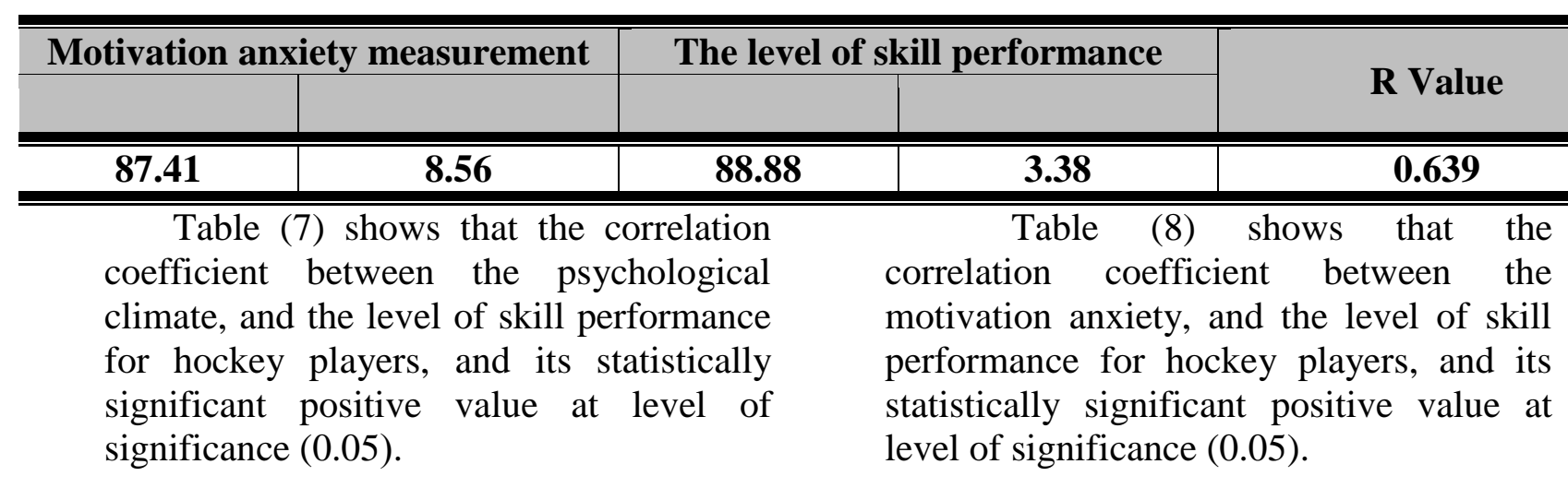

Table (8)

The correlation coefficient between the motivation anxiety measurement, and the level of skill performance.

$\mathbf{N}=\mathbf{1 7}$

\begin{tabular}{|c|c|c|c|c}
\hline \hline \multicolumn{2}{c|}{$\begin{array}{c}\text { The psychological climate } \\
\text { measurement }\end{array}$} & \multicolumn{2}{|c|}{ Motivation anxiety measurement } & \multirow{2}{*}{ R Value } \\
\hline & & & & \\
\hline \hline 93.58 & 4.07 & 87.41 & 8.56 & 0.624 \\
\hline \hline
\end{tabular}

The value of tabulated $(R)$ at the level $0.05=0.482$

Table (8) shows that the correlation between the motivation anxiety, and the level of skill performance for hockey

players, and its statistically significant positive value at level of significance $(0.05$ 


\section{Discussion}

In the light of the research objectives, and within the community and the research sample, the researcher will discuss the research results, through the research hypotheses as follows:

Table (5) shows that the characterization of the statistical sample of basic research, in the items psychological climate scale, indicates that the sample has a climate-psychological, the next consecutive (satisfaction - belonging - the attractiveness of relationships cooperation - collective performance - the enthusiasm harmony - the sense of success - positive - mutual communication approval - cohesion - shared tradition - and clear objectives - the rapprochement successful leadership - efficiency - the clarity of the role) Ranging degrees of the arithmetic averages items, between (6.412: $3.824)$, the averages indicate positive psychological climate for the research sample, for Hockey players team the premier league, the researcher attributes to the fact that, Misses hockey team is characterized by its results, always winning the league and the cup, and gets the first place, that's leading to the high psychological climate among the team players, with the exception of the dimensions (of incentives - stability).

This is consistent with the indication to it by, "Allawy" citing "James Hartmann and Jones" that the psychological climate of sport team is a psychological component or composite, that every player in the team is rated clearly, as to the player realizes the psychological climate for her team has its importance in the influence of the sense of satisfaction, and therefore stay as a member of the team, which is consequential for the cohesion of the sport team, (Mohammad Hassan Allawy, 1998).
As it is consistent with the indication to it by, "Ahmed Amin Fawzy and Tariq Badr al-Din" that the good psychological climate for the sport team shows through a sense of the player's belonging to the team, loyalty, stick to it, the dedication for it, take responsibility, and motivation towards training and matches (Ahmed Amin Fawzy and Tariq Badr al-Din .2001).

And agrees with studies of both the "Heba Radwan" (2008), the study of "Ramzi Jaber" (2009), the study of "Colin McLaren, Kevin Spetk and Others" (2015) where indicated their findings to the players of advanced teams distinguish with qualities (cooperation Harmony - stability - belonging leadership - mutual contact - efficiency shared traditions) They also pointed out that there must be clarity of responsibilities and roles, and the ability of sports to express his personality within the team.

The results indicate in table (5) that, the negative psychological climate for the research sample is prevail, hockey team for Misses items (the existence of incentives - stability), whereas the degrees averages ranged from (2.647: 1.824), and the researcher attributes it to the fact that the Sharkia hockey Misses team, do not receive encouragement, financial support and incentives that worthy of the team, making players feel the team instability, as a result of the weakness of support and incentives.

\section{Discussion the results of the first hypothesis:}

Table (6) shows the presence of positive correlation statistically significant , between the psychological climate, motivation anxiety, the researcher attributes to the fact that psychological preparation of the players before participating in the competitions helps to the positive psychological climate, so the players of the team have the ability to 
cohesion, and the face of crisis that they experienced, whenever this has led to the ability to respond to threats, and turn to the competition concern to motivation anxiety, to achieve the goal of the team, and reach to the desired results.

Anxiety is one of the factors that affect the psychological climate for sport team, Anxiety is an emotionally charged, unpleasant case, coupled with instigating resulting from fear, or expectation the danger, and increasing anxiety about the amount to be leading to confusion athletic performance, and his disability, and vice low level of anxiety leads to carelessness, in the face of situations but if the amount of anxiety appropriately, For the situation that faces the player, that was appropriate to issue the desired behavior, to face situations, and be anxiety here is a motivation positive element helps to face situations, experienced by the player, for the issuance of appropriate behavior, and achieve the best results (Ahmed Amin Fawzy, 2003).

Both Ahmed Amin Fawzy and Tariq Badroddin (2001) refer to that the positive psychological climate, and the interaction between the team, makes every player aware of the importance of the team's success, which in turn leads to the quest for behavior, which leads to a win, and to avoid anything that may lead to failure.

This result is also consistent with the results of a study both, Alfrenk et al. (2005) in the (control of anxiety, motivation, and teamwork) are among six factors, the psychological profile of young talented hockey players, as well as consistent with "Ahmad Amin Fawzy" (2003) in that motivation anxiety is one of the factors that affect the psychological climate of sport team, and if the amount of anxiety is suitable for the situation, which faces the player, it was appropriate to issue the desired behavior, to cope with the situation, and to achieve the best results. (Amin Ahmad Fawzi, 2003). then first hypothesis has achieved, which states that "there is a statistically significant correlation between, psychological climate, the level of motivation anxiety for the players of hockey team (the Premier League)

Discussion the results of the second hypothesis:

Table (7) shows the presence of positive correlation statistically significant between, the psychological climate, the level of skill performance, the researcher believes that the positive psychological climate is prevailing between the players of the team that makes them able to carry out required skill duties, during the match period.

This result is consistent with references to "Newton" (1997) that psychological climate is closely related to educational climate, it indicates the meanings and interpretations of subjectivity, which draws players to experience for their clubs, their training, and matches, and these interpretations affect the direction of their motivation, the level of their performance skill.

Also, consistent with what referred by "Ahmed Amin Fawzy and Tariq Badr al-Din" (2001) that psychological climate, and positive interaction between the team, makes every player aware of the importance of the team's success, which in turn leads to the quest for behavior, which leads to the success of the team, and improve the level of skill performance.

That's agrees with the study of, "Salah Mostafa Manasseh" 2002 results in the psychological climate is an important indicator for selection and $t$ raining, and consistent with the results of Ramzy Rasmy Jaber study (2009), which indicates that the positive psychological climate has a significantly impact to the level of skill performance, and achievement for the players in the premier league, and this result consistent with the 
study of both, Morgan Hull and Maria Newton et al. (2016).

Whereas the most important results indicate that there is a correlation statistically significant, between the psychological climate, and sport commitment at the individual level, and the level of the team, also indicated the most important recommendations of the study, it has to be on the trainers, and consultants of sport psychology, to apply the strategies, aimed to facilitating the task, and promoting the positive psychological climate for athletes. Then second hypothesis has achieved, which states that "there is a statistically significant correlation between, psychological climate, the level of skill performance for the players of hockey team (the Premier League).

\section{Discussion the results of the third hypothesis:}

Table (8) shows that the presence of a positive correlation statistically significant, between motivation anxiety ,and the level of skill performance, the researcher attributes to the fact that anxiety is an emotionally charged unpleasant case, coupled with excitation resulting from fear, or expectation the danger, and increasing anxiety for the required amount, leading to confusion of athletic performance, and disability, and vice low level of anxiety, leading to indifference in the face of situations, but if the amount of anxiety is suitable for the situation, which faces the player, it is appropriate to issue the desired behavior, to face situations and the anxiety here is a positive motivation element.

This result is consistent with what indicated by "Ahmad Fawzi Amin" (2003) that motivation anxiety, characterized by the appropriate intensity, and then the appropriate excitation, which helps to cope with the situations which are being exposed by the player to issue appropriate behavior, and achieve the best results.

Also, consistent with indicated by, "Mohammad Hassan Allawy" (1992) that the anxiety is one of the important psychological variables for the athlete, which should maintain his stability, and trying to invest anxiety as a positive motive, to achieve the best sports results.

Also, consistent with indicated by Farouk Alsayed Uthman (2001) that anxiety constitutes an important motivation that helps to succeed, achievement, excellence, Anxiety motivation constitutes as a promotional advantage, to complete the missions, and indicates that there is a relationship between the level of anxiety, and the level of performance, so that when the level of performance up to the peak, that makes the player reaches the required level of anxiety.

\section{Osama Rateb (1990),} Mahmoud Annan (1995), Mostafa Bahy, and others. (2006) indicate that the anxiety is one of important emotions, which if properly controlled, and directed well, so the player reaches the required level of anxiety before and during the match, that serve as a driving force positive performance.

This result is consistent with the study of Hussein Sabhan, Sen Jassem, and Baydaa Khader (2011), which indicated that the state of motivation anxiety among the players has a positive impact on the level of performance, and as a result of The tie break.

This result is consistent with the study of "Adnan Al Dawlaat, Qasim Gowela , and Others" (2012), which indicated the most important results that there is a correlation between the level of anxiety and the level of achievement, and they recommended the attention continuously for the levels of anxiety during matches, and invest the anxiety case that coupled 
with performance to be the motivation for players.

Thus, the third hypothesis has been achieved, which states that "there is a statistically significant correlation between the level of motivation anxiety, and the level of skill performance for the players of hockey team (Premier League)".

\section{Conclusions}

In the light of the outcome of the research results, in the limits of the research sample the researcher has extracted the following:

1 - The psychological climate is dominant for the players of Sharkia hockey team (premier league) is a positive climate, and arrangement consecutive (satisfaction - of belonging - the attractiveness of relationships - cooperation - collective performance - the enthusiasm harmony - a sense of achievement - positivity - mutual communication - Approval - cohesion shared traditions - and clear objectives the rapprochement - successful leadership - efficiency - the clarity of the role).

2 -There is a positive correlation statistically significant, between the psychological climate, the level of anxiety motivation for the players of Sharkia hockey team (Premier League).

3 -There is a positive correlation statistically significant, between the psychological climate, the level of skill performance for the players of Sharkia hockey team (Premier League).

4 -There is a positive correlation statistically significant, between the level of anxiety motivation, the level of skill performance for the players of Sharkia hockey team (Premier League).

\section{Recommendations}

According to the research conclusions and in the limits of the research sample, the researcher recommends the following- :

1 -positive psychological climate initialization to its association with motivation anxiety, for the players of hockey team in particular, and the players of all sports in general.

2 -creating positive psychological climate and its association with the level of skill performance for the players of hockey team.

3 -interesting in Sharkia Hockey team, and give it the right from the state and highlight it, as happens in football and some other sports in Egypt.

4 -conduct similar studies to identify the psychological climate of various sports team 


\section{References}

1 -Ahmed A. Fawzi. (2003).:" Sports Psychology principles (Concepts - applications)", Cairo, Dar Arab Thoughts , 243.

2. Ahmed A. Fawzi, Tariq B. Al-Din (2001):" Sports team psychology", Cairo, Dar Arab Thought, 19,30,102,216.

3. Adam M. Mubarak. (2008). "Perceptions footballers' excellent degree of psychological climate for their clubs and their attitudes towards the spirit of sport", Science and Culture magazine, Vol (9), No. (2), Sudan.

4. Osama k. Rateb (1990):"Motivated superiority in Sports activity", Cairo, Dar Arab Thought, 199.

5. Osama k. Rateb (1997):" Psychological preparation for training young - guide for trainers and parents", Cairo, Dar Arab Thought ,237.

6. Osama k. Rateb (2001):" Psychological skills training (applications in the sports field)", Dar Arab Thought ,3.

7. Allen Faraj. (2008):" Field's hoky scientific bases and training", knowledge origin, Alexandria, 32,33.

8. Hussein Sabhan, Wson Jassim, Bydaa Khedr (2011):"Some types of anxiety and its relationship to the outcome of the decisive half of the players some excellent clubs Iraq, mainly in volleyball", research published in the eighth Conference, Faculty of Physical Education in Iraq, Baghdad University.

9. Ramzy R. Jaber. (2009). "A study of climate Psychiatric handball teams and its relationship to the phenomenon of their achievement in the league Palestinian excellent", research published in the first Scientific Conference of the Faculty of Physical Education, University of Palestine success.

10. Salah M. Mansy (2002):"Psychological climate for some national teams in team sports as an indicator for the selection and training in Kuwait".

11. Abdel Moneim Shehata (2002):"I and the other mutual relations psychology, 2nd edition, Dar Etrak for publication and distribution ,85.

12. Adnan Aldwlat, Qasim Joalh, Others (2012): "The impact of psychological anxiety of the players badminton and its relationship to the level of achievement", research published in the Al-Najah University Research and Humanities Journal, Vol. 26, No. 5.

13. Alia A. Shawky. (2008):" Tennis games (hockey, table tennis)", Alexandria, Dar Alwafaa for Printing \& Publishing ,81.

14. Farouk Al.osman. (2001):" Stress and mental anxiety management ", Cairo, Dar Arab Thought, 26 and 28.

15. Kamal A.AlMaksood (2014):" Alternative Journal article", 12/09/2014.

16. Mohammed H. Allawy (1992):" Sports psychology", Cairo, Dar Almaaref .278.

17. Mohammed H. Allawy (1998):" The psychology of sports groups", book publishing center ,from 39 to 99.

18. Mohamed H. Allawy., Kamal Darwish, Emad. Abbas (2003):"Psychological preparation in handball (theories - applications)", Cairo, book publishing center ,443. 
19 - Mahmoud A. Annan. (1995):"Psychology of Physical Education and Sport (theory and practice and experimentation)", Cairo, Dar Arab Thought ,272.

20. Mahmoud A. Annan., Mustafa H. Bahy (2000):"Introduction in sports psychology", Cairo, book publishing center.

21. Mustafa H. Bahy , Smir Jad. (2006) :" athletic performance psychology (Theoriesanalysis - applications)", Anglo Egyptian library ,257 to 260.

22. Nihal S.Ebadh (2011): "Psychological skills Special Hockey East players and their relationship to the level of performance", research published in the Journal of Comprehensive Education Faculty of Physical Education for Girls, Zagazig University. Vol.1 of the second half of 2011, S.s 1:27.

23.Heba R. Labib. (2008). "Communication and listening skills of trainers and handball players and their relationship psychological climate for the team and the results of the matches" summaries Research Third International Scientific Conference, Faculty of Physical Education Zagazig University, Egypt.

24. Yahya K.Alnaqeeb (1990):" sports psychology science", Leadership Development Institute, Saudi Arabia ,39.

25- Colin D. McLaren, Kevin S. Spink\& Kathleen S. Wilson. (2015).25:" Exploring the relationship between psychological climate and athlete satisfaction across sex and competitive sport levels, Journal of Exercise, Movement, and Sport, Vol 47, No 1.

http://jps.library.utoronto.ca/index.php/jems/article/view/25436

26- El -ferink Gemser, et al. (2006). Psychological characteristics of talented youth athletes in field hockey, basketball, volleyball, speed skating and swimming.

http:// dissertaationsub.rug.n/fites/facultees/ppsw/2005/m.t.elfere-gamser/colbdf

27-Morgan Hall, Maria Newton, Aubrey Newland\& Brian R.W Baucom (2016): Perceptions of the Social Psychological Climate and Sport Commitment in Adolescent Athletes: A Multilevel Analysis, Journal of Applied Sport Psychology • April .https://www.researchgate.net/publication/29999760

28-Newton M. (1997). The relationship between the psychological climate of teams and player motivation Avca online.

https:/www.avca.org/sportsmed/smpcarticles/smpcpsychomotivation.html. 